\title{
Public health implications of sleep loss: the community burden
}

\begin{abstract}
David R Hillman
MB BS, FANZ , FANZCA, FRCPE
Sleep Physician

Leon C Lack Lack
PhD, Professor of Psychology

1 Department of Pulmonary Physiology and Sleep Medicine, Sir Charles Gairdner Hospital, Perth, WA.

2 School of Psychology, Flinders University,

Adelaide, SA.

David.Hillman@ health.wa.gov.au
\end{abstract}

MJA 2013; 199: S7-S10 doi: 10.5694/mjal3.10620

Online first 17/10/13 leep is a basic and necessary biological process that demands to be satisfied as much as our need for food and drink. Inadequate sleep can occur if insufficient time is allowed for it or if a disorder is present that disturbs sleep quality. It is only recently that we have begun to understand the scale of the health and social consequences of insufficient sleep and sleep disorders. Sleep loss from these problems is associated with disturbances in cognitive and psychomotor function including mood, thinking, concentration, memory, learning, vigilance and reaction times. ${ }^{1,2}$ These disturbances have adverse effects on wellbeing, productivity and safety. Insufficient sleep is a direct contributor to injury and death from motor vehicle and workplace accidents. ${ }^{3}$ Further, relationships have been demonstrated between shortened sleep and a range of health problems including hypertension, ${ }^{4}$ type 2 diabetes, ${ }^{5}$ obesity, ${ }^{6}$ cardiovascular disease ${ }^{7,8}$ and total mortality risk. ${ }^{9}$ Specific sleep disorders such as insomnia, ${ }^{10}$ obstructive sleep apnoea (OSA) ${ }^{11}$ and restless leg syndrome ${ }^{12}$ have also been associated with increased morbidity and mortality. These sleep-related problems incur financial costs relating to health and other expenditures and non-financial costs relating to loss of quality of life. This article considers the prevalence and economic impacts of sleep problems in Australia.

\section{Prevalence of sleep problems}

There have been very few studies of the prevalence of disturbed sleep in Australia. A small survey $(n=216)$ of sleeping difficulties, daytime sleepiness and hypnotic medication use was conducted in Adelaide more than 20 years ago. ${ }^{13}$ A larger survey $(n=535)$ was conducted in Newcastle, New South Wales, in 1996 but was limited to a question about insomnia and hypnotic medications. ${ }^{14}$ Another small survey $(n=267)$ in rural Victoria among Australian day workers was heavily weighted to men. ${ }^{15}$ More recently, a large NSW mail survey $(n=3300)$ reported that $18.4 \%$ of participants slept less than 6.5 hours a night and $11.7 \%$ complained of chronic sleepiness. ${ }^{16} \mathrm{~A}$ recent study of the insomnia burden suggested a prevalence of $5.6 \%$, with increased use of health care. ${ }^{17}$

To further characterise sleep quality in a large representative sample of Australians, in 2010, the Sleep Health Foundation (www.sleephealthfoundation.org.au) commissioned a national survey of sleeping difficulties and negative daytime consequences of poor sleep. It was modelled on the Sleep in America surveys conducted by the National Sleep Foundation, in part to allow international comparisons. A national polling organisation (Roy Morgan Research) was commissioned to perform the work. It conducted a national landline telephone survey of adolescents and adults (14 to $>70$ years of age) across successive weekend evenings. The survey contained 14 questions about sleep: five about sleeping difficulty, two about snor-

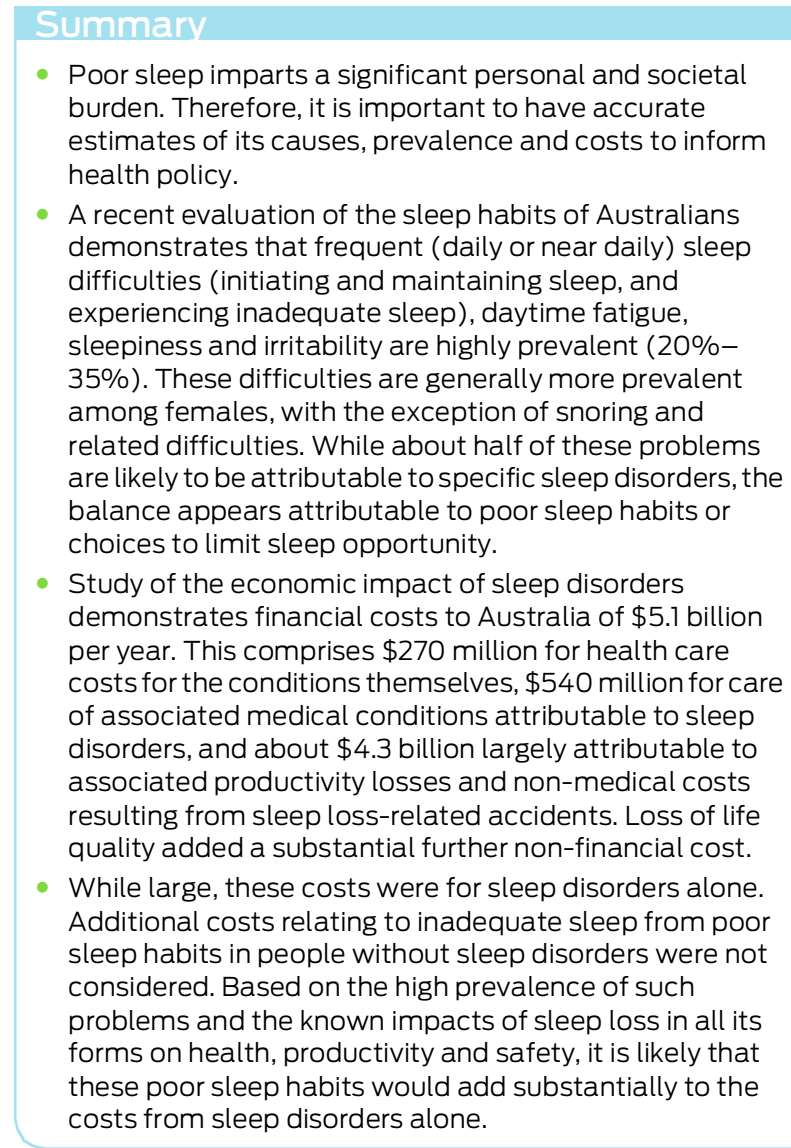

ing and OSA, one about restless legs, one about sleeping medication, three about daytime impairments usually associated with sleep disturbance, and two about nocturnal sleep duration (weekdays and weekends) (Box 1). There were 1512 respondents from all states and territories, both urban and rural, with sampling proportionate to the populations of those areas, sex and age.

Box 1 shows the proportions of respondents reporting current sleep difficulties and daytime impairments at least a few times per week (indicative of significant problem), as well as average self-reported sleep duration for the population overall, for males and females, and for each age group. The results illustrate that a considerable proportion of Australians report frequent sleeping difficulties. Overall, $20 \%$ of respondents had frequent difficulty falling asleep, which was more prevalent among females and younger age groups. Frequent waking during the night was reported by $35 \%$ overall, again more commonly among females but increasing with age. Thirty-five per cent reported waking unrefreshed and $24 \%$ reported inadequate sleep. Daytime sleepiness, fatigue/exhaustion and irritability were common issues (19\%-24\%).

Symptoms were examined to determine likely prevalence of insomnia by selecting those with specific self- 
1 Proportions of survey respondents experiencing sleep difficulties, sleep disorder symptoms and daytime impairments a few times a week or more (often), overall and by sex and age group

\begin{tabular}{|c|c|c|c|c|c|c|c|c|c|}
\hline \multirow[b]{2}{*}{ Difficulty experienced often } & \multirow[b]{2}{*}{ Overall } & \multicolumn{2}{|c|}{ Sex } & \multicolumn{6}{|c|}{ Age group } \\
\hline & & Male & Female & $14-17$ years & $18-24$ years & $25-34$ years & $35-49$ years & $50-64$ years & $\geqslant 65$ years \\
\hline Weighted proportion of total & $100 \%$ & $49.4 \%$ & $50.6 \%$ & $6.4 \%$ & $11.7 \%$ & $17.4 \%$ & $26.0 \%$ & $21.9 \%$ & $16.5 \%$ \\
\hline \multicolumn{10}{|l|}{ Sleeping difficulty } \\
\hline Difficulty falling asleep & $19.6 \%$ & $16.9 \%$ & $22.4 \% *$ & $33.6 \%{ }^{\dagger}$ & $32.2 \%^{\dagger}$ & $17.6 \%$ & $20.0 \%$ & $14.6 \%$ & $13.5 \%$ \\
\hline Waking a lot during night & $34.9 \%$ & $30.4 \%$ & $39.3 \%{ }^{\dagger}$ & $21.2 \%$ & $28.1 \%$ & $32.6 \%$ & $42.6 \%{ }^{\dagger}$ & $31.8 \%$ & $39.5 \%{ }^{\dagger}$ \\
\hline Waking up too early & $25.3 \%$ & $22.9 \%$ & $27.7 \% *$ & $19.5 \%$ & $23.4 \%$ & $20.3 \%$ & $29.1 \% *$ & $25.5 \%$ & $27.9 \% *$ \\
\hline Waking feeling unrefreshed & $34.7 \%$ & $31.8 \%$ & $37.6 \% *$ & $38.1 \%^{\dagger}$ & $44.0 \%{ }^{\dagger}$ & $42.0 \%{ }^{\dagger}$ & $39.8 \%{ }^{\dagger}$ & $28.5 \%$ & $19.3 \%$ \\
\hline Did not get adequate sleep & $23.7 \%$ & $17.9 \%$ & $29.4 \%{ }^{\dagger}$ & $24.9 \%^{\dagger}$ & $29.3 \%^{\dagger}$ & $25.3 \%^{\dagger}$ & $24.5 \%{ }^{\dagger}$ & $21.4 \%$ & $19.3 \%$ \\
\hline \multicolumn{10}{|l|}{ Snoring, obstructed breathing } \\
\hline Frequent or loud snoring ${ }^{\ddagger}$ & $21.2 \%$ & $26.4 \%{ }^{\dagger}$ & $12.1 \%$ & $8.4 \%$ & $8.6 \%$ & $21.7 \%^{\dagger}$ & $23.5 \%^{\dagger}$ & $20.0 \%{ }^{\dagger}$ & $20.0 \%^{\dagger}$ \\
\hline Pauses in breathing in sleep $\ddagger$ & $6.6 \%$ & $6.2 \%$ & $5.1 \%$ & $2.9 \%$ & $4.4 \%$ & $3.8 \%$ & $4.6 \%$ & $7.8 \% *$ & $8.4 \% *$ \\
\hline Restless legs & $9.4 \%$ & $8.6 \%$ & $10.3 \%$ & $4.0 \%$ & $5.3 \%$ & $11.2 \%^{\dagger}$ & $7.2 \%$ & $10.7 \%^{\dagger}$ & $14.5 \%^{\dagger}$ \\
\hline Prescribed sleep medication use & $3.6 \%$ & $4.0 \%$ & $3.1 \%$ & $3.5 \%$ & $2.5 \%$ & $1.8 \%$ & $2.4 \%$ & $5.8 \%^{\dagger}$ & $5.4 \%{ }^{\dagger}$ \\
\hline \multicolumn{10}{|l|}{ Daytime symptoms } \\
\hline Daytime sleepiness & $19.0 \%$ & $15.7 \%$ & $22.3 \% *$ & $24.6 \%{ }^{\dagger}$ & $26.2 \%^{\dagger}$ & $21.1 \%^{\dagger}$ & $22.4 \%{ }^{\dagger}$ & $13.6 \%$ & $11.4 \%$ \\
\hline Fatigue or exhaustion & $23.5 \%$ & $20.0 \%$ & $27.0 \%{ }^{\dagger}$ & $22.8 \%$ & $27.7 \%^{\dagger}$ & $27.7 \%^{\dagger}$ & $29.1 \%^{\dagger}$ & $18.8 \%$ & $14.2 \%$ \\
\hline Irritable or moody & $18.8 \%$ & $18.2 \%$ & $19.3 \%$ & $18.8 \%$ & $19.2 \%$ & $27.9 \%{ }^{\dagger}$ & $22.9 \%^{\dagger}$ & $12.9 \%$ & $9.8 \%$ \\
\hline \multicolumn{10}{|l|}{ Sleep duration } \\
\hline Weeknights (Sunday-Thursday), h & 7.16 & 7.15 & 7.17 & $8.24^{\dagger}$ & $7.49 *$ & 7.18 & 6.86 & 7.01 & $7.14 *$ \\
\hline Weekend nights (Friday, Saturday), h & 7.37 & 7.37 & 7.37 & $8.45^{\dagger}$ & 7.37 & 7.54 & 7.19 & 7.29 & 7.14 \\
\hline Overall, h & 7.22 & 7.21 & 7.23 & $8.30^{\dagger}$ & $7.46 *$ & 7.28 & 6.95 & 7.09 & $7.14 *$ \\
\hline \multicolumn{10}{|l|}{ Sleep disorder estimates } \\
\hline Severe clinical insomnia ${ }^{5}$ & $6.9 \%$ & $5.0 \%$ & $8.7 \% *$ & $2.0 \%$ & $11.3 \% *$ & $4.2 \%$ & $10.1 \% *$ & $6.9 \%$ & $3.8 \%$ \\
\hline Sleep apnoea $a^{\ddagger, 9}$ & $4.9 \%$ & $6.3 \% *$ & $3.6 \%$ & 0 & $2.2 \%$ & $2.1 \%$ & $4.7 \%$ & 7.7\%* & $7.0 \% *$ \\
\hline
\end{tabular}

$* P<0.05 . \dagger P<0.001$. $¥$ Adjusted for the 10\%-11\% who "can't say". $§$ Estimated Insomnia Severity Index $>14$, derived from data for sleeping difficulty and daytime symptoms. Я Estimates derived from data for frequent breathing pauses and loud snoring.

reported sleep difficulties plus daytime impairment ${ }^{18}$ to derive a score that very closely simulates the Insomnia Severity Index, a highly reliable and valid tool to identify clinical insomnia. ${ }^{19}$ This suggested an overall presence of severe insomnia (Insomnia Severity Index, $>14$ ) of $6.9 \%$, $8.7 \%$ in women and $5 \%$ in men (Box 1 ).

Prevalence of sleep apnoea was derived by determining the proportion of respondents who snored loudly at least a few times a week and had observed breathing pauses during sleep at least a few times a month. An overall prevalence of $4.9 \%$ was noted, but in this case, prevalence was higher among males (6.4\%) than females (3.6\%).

While these prevalences of specific sleep disorders were derived from combinations of questionnaire responses, they are similar to the prevalences determined from other population-based studies. ${ }^{10,20}$ These findings suggest that specific sleep disorders may account for about half of the complaints of daytime sleepiness and fatigue and exhaustion noted in our survey. While other health problems can disturb sleep, particularly in older patients, much of the balance may be due to insufficient sleep duration by choice or through circumstances that result in sleep being given a lower priority than work, social or family activities. Sleep duration estimates are significantly below the putative average adolescent sleep requirement of 9 hours a night and adult sleep requirement of 7.5-8 hours a night for both men and women, particularly among those between the ages of 35 and 65 years. ${ }^{21}$ Insufficient sleep at least a few times a week was reported by $23.7 \%$ of the sample, more frequently by females, and more commonly in the younger to middle-aged groups. Perhaps relevant to this, a study of young adults has shown that those with shorter habitual sleep patterns carried the highest sleep debt, suggesting self-selected sleep restriction. ${ }^{22}$

The general point that emerges from these data is that inadequate sleep (duration or quality) and its daytime consequences are widely prevalent in Australians, either because of a specific sleep-related disorder or from voluntarily shortened sleep through choice or circumstance. Although there are limitations with telephone surveys (eg, low response rates to landline phone calls), the results are very comparable with those observed in similar surveys conducted elsewhere, such as the 2008 Centers for Disease Control and Prevention study, which reported that $28 \%$ of United States adults had insufficient sleep or rest $(<7 \mathrm{~h} /$ night) on most nights over a 30 -day survey period. ${ }^{23}$

\section{Economic impact}

Poor sleep and its consequences result in significant costs to the community. Although there have been no detailed economic evaluations of the costs associated with insufficient sleep in otherwise healthy individuals, analyses have been undertaken for those with sleep disorders. ${ }^{24,25}$ OSA provides an example of a widely prevalent sleep disorder with significant comorbidities, including impaired daytime alertness, increased accident risk, hypertension, vascular 


\begin{tabular}{lc}
2 Summary of the annual costs of sleep disorders and \\
associated conditions, 2010 \\
Variable & AUD (million) \\
\hline Direct health care cost & 274 \\
Sleep disorders & 544 \\
Associated conditions* & \\
Indirect financial cost & 3132 \\
Productivity & 129 \\
Informal care for accident victims & 465 \\
Other cost of motor vehicle accidents & 53 \\
Other cost of workplace accidents & 472 \\
Deadweight loss to taxation system & 5069 \\
\hline Total financial cost & 31350 \\
\hline Non-financial cost & 36419 \\
\hline Loss of disability-adjusted life-years & \\
\hline Total economic cost & \\
\hline * Hypertension, vascular disease, depression, motor vehicle injuries and \\
workplace injuries.
\end{tabular}

disease and depression. ${ }^{20}$ The associated costs include the direct care-related health costs of the sleep disorder itself and the costs of medical conditions occurring as a result of them. In addition, there are substantial indirect financial and non-financial costs. Other financial costs include the non-health costs of work-related injuries, motor vehicle accidents and productivity losses - all common consequences of insufficient sleep. Non-financial costs derive from loss of quality of life and premature death. ${ }^{24}$

In 2011, the Sleep Health Foundation commissioned Deloitte Access Economics, a national economics consultancy with a strong health economics background, to undertake an analysis of the direct and indirect costs associated with sleep disorders for the 2010 calendar year. ${ }^{25}$ The methods used were similar to those that they had used in a previous evaluation. ${ }^{24}$ Such an analysis requires robust data relating to the prevalence of the sleep disorder under consideration, the prevalences and costs associated with conditions with which it has a causal relationship, and the risk ratios describing the strength of these relationships. Using these data, the proportion of each condition attributable to the sleep disorder (the attributable fraction) can be derived. Specifying the prevalences and odds ratios used to calculate attributable fractions imparts transparency to the assumptions involved in calculating them. The fraction can then be used to derive the share of the costs associated with that condition that is attributable to the particular sleep disorder under consideration. Using these methods, Deloitte Access Economics examined costs associated with the three most common sleep disorders — OSA, primary insomnia and restless legs syndrome - as the robust data required for analysis were available. $^{25}$ It estimated total health care costs of $\$ 818$ million per year for these conditions, comprising \$274 million for the costs of caring for the disorders themselves and $\$ 544$ million for conditions associated with them. Of these costs, $\$ 657$ million per year related to OSA: \$248 million for OSA itself and $\$ 409$ million for the health costs of conditions attributable to OSA. These conditions include hypertension, vascular disease, depression, and motor vehicle and workplace accidents. The analysis suggested that $10.1 \%$ of depression, $5.3 \%$ of stroke, $4.5 \%$ of workplace injuries and $4.3 \%$ of motor vehicle accidents are attributable to a sleep disorder.

The indirect financial and non-financial costs associated with sleep disorders are much greater than the direct costs. The indirect financial costs were estimated to be $\$ 4.3$ billion in 2010. These included $\$ 3.1$ billion in lost productivity and $\$ 650$ million in informal care and other indirect costs resulting from motor vehicle and workplace accidents. Of these indirect costs, OSA accounted for $61 \%$ ( $\$ 2.6$ billion), primary insomnia for 36\% (\$1.5 billion) and restless leg syndrome for 3\% (\$115 million).

The report also estimated the effect of sleep disorders on loss of quality of life in terms of disability-adjusted lifeyears. These costs were calculated using the proportion of total national health costs attributable to sleep disorders to proxy the proportionality of the total national disease burden attributable to these problems. A dollar cost was calculated from the product of these years lost (190 000) and the value of a statistical life-year $(\$ 165000)$. This added a further non-financial cost of $\$ 31.4$ billion to the total economic cost of sleep disorders (Box 2). The nonfinancial nature of this cost gave it less tangibility than financial costs, but the calculation does draw attention to the substantial burden associated with the loss of quality of life resulting from sleep disorders.

As large as they are, these costs are likely to significantly underestimate the total cost to the community of sleeprelated problems. Deloitte Access Economics evaluated costs associated with common sleep disorders. The costs of accidents and illnesses associated with sleep loss resulting from poor sleep habits from personal choice and/or from conflicting priorities such as work, social or family activities were not considered as they are difficult to estimate. Further, the analysis used conservative estimates of the prevalence of sleep disorders. For example, the base prevalence of OSA used was $4.7 \%$, which is below the proportion of moderate OSA observed in many contemporary studies, a proportion which is likely to increase further as the population ages and becomes more obese. ${ }^{20}$ The prevalence of insomnia used in the analysis was also low at $3 \%$, a figure based on primary insomnia estimates. ${ }^{26} \mathrm{Sec}-$ ondary insomnias resulting from other causes were not considered. Our own estimate including all insomnia from a representative Australian sample (Box 1) was closer to $7 \%$. Potential comorbidities of sleep disorders, even if reasonable evidence for an association existed (such as metabolic disorders in the case of OSA), were also excluded from consideration. Finally, the analysis did not cost some aspects of the known comorbidities of sleep disorders, such as the impact of presenteeism (being present at work but operating suboptimally) on productivity and safety. The reason for this omission was the difficulty in reliably quantifying its effects.

\section{Conclusion}

Poor or inadequate sleep is very common among Australian adolescents and adults, affecting over $20 \%$ on a daily or near-daily basis. Epidemiological studies suggest about 
half of this problem can be attributable to common sleep disorders such as OSA and insomnia, as together they affect about $10 \%$ of the community. The balance appears likely to be the result of inadequate sleep arising from other health problems or issues such as poor sleep habits or sleep loss because of competing demands on time from work, social or family activities. Economic estimates demonstrate that sleep disorders are associated with large financial and non-financial costs. Given that the greatest financial costs appear to be non-medical costs related to loss of productivity and accident risk, it is likely that inclusion of the effects of sleep restriction from poor sleep habits or choice could add considerably to these already substantial amounts.

Competing interests: No relevant disclosures.

Provenance: Commissioned by supplement editors; externally peer reviewed.

1 Institute of Medicine (US) Committee on Sleep Medicine and Research; Colten HR, Altevogt BM, editors. Sleep disorders and sleep deprivation: an unmet public health problem. Washington, DC: The National Academies Press, 2006.

2 Dinges DF, Pack F, Williams K, et al. Cumulative sleepiness, mood disturbance, and psychomotor vigilance performance decrements during a week of sleep restricted to 4-5 hours per night. Sleep 1997; 20: 267-277.

3 Stutts JC, Wilkins JW, Scott Osberg J, Vaughn BV. Driver risk factors for sleeprelated crashes. Accid Anal Prev 2003; 35: 321-331.

4 Vgontzas AN, Liao D, Bixler EO, et al. Insomnia with objective short sleep duration is associated with a high risk for hypertension. Sleep 2009; 32: 491-497.

5 Spiegel K, Knutson K, Leproult R, et al. Sleep loss: a novel risk factor for insulin resistance and type 2 diabetes. J Appl Physiol 2005; 99: 2008-2019.

6 Watanabe M, Kikuchi H, Tanaka K, Takahashi M. Association of short sleep duration with weight gain and obesity at 1-year follow-up: a large-scale prospective study. Sleep 2010; 33: 161-167.

7 Sabanayagam C, Shankar A. Sleep duration and cardiovascular disease: results from the National Health Interview Survey. Sleep 2010; 33: 1037-1042.

8 Bagai K. Obstructive sleep apnea, stroke, and cardiovascular diseases. Neurologist 2010; 16: 329-339.
9 Grandner MA, Hale L, Moore M, Patel NP. Mortality associated with short sleep duration: the evidence, the possible mechanisms, and the future. Sleep Med Rev 2009; 14: 191-203.

10 Léger D, Guilleminault C, Bader G, et al. Medical and socio-professional impact of insomnia. Sleep 2002; 25: 625-629.

11 Bagai K. Obstructive sleep apnea, stroke, and cardiovascular diseases. Neurologist 2010; 16: 329-339.

12 Garcia-Borreguero D, Egatz R, Winkelmann J, Berger K. Epidemiology of restless legs syndrome: the current status. Sleep Med Rev 2006; 10: 153-167.

13 Lack L, Miller W, Turner DA. A survey of sleeping difficulties in an Australian population. Community Health Stud 1988; 12: 200-207.

14 Olson LG. A community survey of insomnia in Newcastle. Aust N Z J Public Health 1996; 20: 655-657.

15 Johns M, Hocking B. Daytime sleepiness and sleep habits of Australian workers. Sleep 1997; 20: 844-849.

16 Bartlett DJ, Marshall NS, Williams A, Grunstein RR. Sleep health New South Wales: chronic sleep restriction and daytime sleepiness. Intern Med J 2008; 38 : 24-31.

17 Bin YS, Marshall NS, Glozier N. The burden of insomnia on individual function and healthcare consumption in Australia. Aust NZ J Public Health 2012; 36: 462-468.

18 National Institutes of Health. NIH State of the Science Conference statement on manifestations and management of chronic insomnia in adults, June 13-15, 2005. Sleep 2005; 28: 1049-1057.

19 Bastien CH, Vallieres A, Morin CM. Validation of the Insomnia Severity Index as an outcome measure for insomnia research. Sleep Med 2001; 2: 297-307.

20 Young T, Peppard PE, Gottlieb DJ. Epidemiology of obstructive sleep apnea: a population health perspective. Am J Respir Crit Care Med 2002; 165: 1217-1239.

21 Krueger PM, Friedman EM. Sleep duration in the United States: a crosssectional population-based study. Am J Epidemiol 2009; 169: 1052-1063.

22 Klerman EB, Dijk D-B. Interindividual variation in sleep duration and its association with sleep debt in young adults. Sleep 2005; 28: 1253-1259.

23 Centers for Disease Control and Prevention. Perceived insufficient rest or sleep among adults - United States, 2005-2008. MMWR 2011; 60: 239-242.

24 Hillman DR, Murphy AS, Antic R, Pezzullo L. The economic costs of sleep disorders. Sleep 2006; 29: 299-305.

25 Deloitte Access Economics. Re-awakening Australia: the economic cost of sleep disorders in Australia, 2010. Canberra, Australia: Deloitte Access Economics, 2011. http://www.sleephealthfoundation.org.au/pdfs/news/ Reawakening\%20Australia.pdf (accessed Jun 2013).

26 Ohayon MM, Caulet, M, Priest, RG, Guilleminault C. DSM-IV and ICSD-90 insomnia symptoms and sleep dissatisfaction. Br J Psychiatry 1997; 171: 382-388. 